\title{
In vitro antifungal activity of Cinnamomum zeylanicum bark and leaf essential oils against Candida albicans and Candida auris
}

\author{
Hoang N. H. Tran ${ }^{1}$ - Lee Graham ${ }^{2}$ - Emmanuel C. Adukwu ${ }^{2}$
}

Received: 27 May 2020 / Revised: 16 July 2020 / Accepted: 11 August 2020 / Published online: 3 September 2020

(C) The Author(s) 2020

\begin{abstract}
Candida infections are a significant source of patient morbidity and mortality. Candida albicans is the most common pathogen causing Candida infections. Candida auris is a newly described pathogen that is associated with multi-drug-resistant candidiasis and candidaemia in humans. The antifungal effects of various essential oils and plant compounds have been demonstrated against human pathogenic fungi. In this study, the effect of cinnamon leaf and bark essential oils (CEOs) was determined against both C. albicans and $C$. auris. The disc diffusion (direct and vapour) and broth microdilution method was used to determine antifungal activity of the EOs against selected strains (C. albicans ATCC 10231, C. albicans ATCC 2091 and C. auris NCPF 8971) whilst the mode of action and haemolysin activity of the CEOs were determined using electron microscopy and light microscopy. Direct and vapour diffusion assays showed greater inhibitory activity of bark CEO in comparison with leaf CEO. The minimum inhibitory concentrations (MICs) and minimum fungicidal concentrations (MFCs) of bark CEO for all tested strains was below $0.03 \%(v / v)$, which was lower than the MICs of the leaf CEO $(0.06-0.13 \%, v / v)$ dependent on the strain and the MFCs at $0.25 \%(v / v)$. In the morphological interference assays, damage to the cell membrane was observed and both CEOs inhibited hyphae formation. The haemolysin production assay showed that CEOs can reduce the haemolytic activity in the tested C. albicans and C. auris strains. At low concentrations, CEOs have potent antifungal and antihaemolytic activities in vitro against $C$. albicans and C. auris.
\end{abstract}

\section{Key points}

- Essential oils from Cinnamomum zeylanicum Blume bark and leaf (CBEO and CLEO) demonstrated fungicidal properties at very low concentrations.

- The antifungal activity of CBEO was greater than that of CLEO consistent with other recent published literature.

- The mode of action of CBEO and CLEO was damage to the membrane of C. albicans and C. auris.

- Both CBEO and CLEO inhibited the formation of hyphae and reduced haemolysin production in C. albicans and C. auris.

Keywords Candida infections $\cdot$ Antifungal $\cdot$ Antihaemolytic $\cdot$ Essential oil $\cdot$ Cinnamon

The work was conducted at the Centre for Research in Biosciences, University of the West of England, Coldharbour Lane, Bristol, BS16 1QY UK.

\section{Emmanuel C. Adukwu}

emmanuel.adukwu@uwe.ac.uk

Hoang N. H. Tran

hoangtran.tnhh@gmail.com

Lee Graham

lee.graham@uwe.ac.uk

1 Faculty of Life Sciences, School of Physiology, Pharmacology and Neuroscience, University of Bristol, Bristol BS8 1TH, UK

2 Centre for Research in Biosciences, University of the West of England, Coldharbour Lane, Bristol BS16 1QY, UK

\section{Introduction}

Fungal infections are common diseases of the natural world. In humans, fungal infections occur when the immune system is unable to deal with a considerable amount of trespassing fungi or yeast invading an area of the body. There are several classes of fungal infections, and of these, Candida infections are regarded as a significant cause of patient morbidity and mortality (Sardi et al. 2013). Candida infections are caused by commensal fungi Candida spp., especially Candida albicans, which resides on the skin, mucosa and gastrointestinal tract of 30 to $50 \%$ of healthy adults at any given time, with everyone being colonized at some point in their lifetime (Brown and Netea 2007). Candida auris is a newly described opportunistic 
pathogen, which grows as yeast. C. auris is known to be resistant to several classes of antifungal drugs including the first-line antifungal, fluconazole, and exhibits variable susceptibility to other azoles, amphotericin B, and echinocandins (Chowdhary et al. 2016). Additionally, C. auris has a potential for person-toperson transmission, challenging clinicians and infection control teams (Ben-Ami et al. 2017).

Essential oils (EOs) are considered plant-originated complex liquid mixtures of volatile and low molecular weight substances (Amorati et al. 2013; Raut and Karuppayil 2014). Recently, natural products extracted from traditional medicine have contributed to the development of innovative modern drugs (Yunes et al. 2005; Almeida et al. 2001). Antifungal activity against various plant and human pathogenic fungi including yeasts have been discovered in numerous EOs (Raut and Karuppayil 2014; Chen et al. 2013; Bajpai et al. 2009; Li et al. 2014). Cinnamomum zeylanicum Blume (a synonym of Cinnamon verum J. Presl) commonly known as Sri Lanka cinnamon is widely cultivated in India, China, Sri Lanka, and Australia (Prasad et al. 2009). The EOs made from its leaf and bark have been described as having useful antiseptic, immunostimulant, detoxifying, analgesic and antidepressant effects (Thosar et al. 2013; Gautam et al. 2014; Vaseeharan and Thaya 2014; Tworkoski 2002; Topa et al. 2018).

In India, Dalchini (C. zeylanicum Blume bark) is often soaked in water and used as mouthwash solution to treat dental caries pathogens. The study of Aneja et al. (2009) showed that Dalchini extract exhibits even much higher antifungal activity than the standard antifungal drug amphotericin-B on oral pathogens including Saccharomyces cerevisiae and C. albicans. In addition, the extraction of cinnamon leaf and bark demonstrated inhibitory activity against Fusarium graminearum, F. proliferatum, Aspergillus fumigatus and Trichophyton rubrum in previous studies (Velluti et al. 2003; Velluti et al. 2004; Khan and Ahmad 2011). In the study by Carvalho et al. (2018), CEOs extracted from $C$. zeylanicum were shown to inhibit some virulence factors in clinical strains of $C$. albicans such as proteinase production, germ tube formation and adhesion to buccal epithelial cells. Moreover, previous studies have reported that cinnamaldehyde and eugenol, which are the main components of bark and leaf cinnamon essential oils, respectively, have demonstrated active in vitro tested against dermatophyte strains isolated from patients with dermatophytosis inhibiting $80 \%$ of the dermatophyte strains tested (Gruenwald et al. 2010). However, to our knowledge, there is little data available demonstrating the possibility of utilizing CEOs to treat infections caused by $C$. albicans and no evidence to date of EO activity against $C$. auris.

The focus of this study was to investigate the antifungal activities and the antihaemolytic effects of the oils extracted from leaf and bark of C. zeylanicum Blume against C. albicans and C. auris.

\section{Methods}

\section{Fungal organisms}

Three organisms were used in this study which included two strains of C. albicans: ATCC 10231 and ATCC 2091 and one strain of $C$. auris: NCPF 8971. The $C$. albicans strains were provided by the Southmead Hospital, Bristol, UK while the C. auris was purchased from the National Collection of Pathogenic Fungi (NCPF) operated by Public Health England (UK). The organisms were maintained on Sabouraud Dextrose agar (SDA, CM0041, Oxoid Ltd., UK) at 30 and $4{ }^{\circ} \mathrm{C}$ until used in tests. The inoculum was prepared from $C$. albicans and C. auris cultures, plated on SDA and incubated at $30^{\circ} \mathrm{C}$ for $48 \mathrm{~h}$ and prior to each experiment, was standardized using 0.5 McFarland with a final concentration at approximately $10^{6}$ colony-forming units per millilitre $(\mathrm{CFU} / \mathrm{mL})$.

\section{Essential oils used in this study}

The bark CEO (Cinnamomum zeylanicum Blume; CBEO) was donated by Amphora Aromatics Ltd., UK for research purposes and the leaf CEO (Cinnamomum zeylanicum Blume; CLEO) was purchased from Freshskin Beauty Ltd., UK. The EOs were kept at room temperature throughout the experimental period.

\section{Gas chromatography mass spectroscopy}

Using similar methods to Zeng et al. (2015), gas chromatography mass spectroscopy (GC-MS) analysis was performed using the Agilent $6890 \mathrm{~N}$ Gas Chromatograph system (Agilent Technologies, USA) to identify the component profiles in the tested oils. Data acquisition and analysis was performed using the Agilent MassHunter software (Agilent Technologies, USA) based on the retention times and mass spectra.

\section{Antifungal susceptibility testing using the disc diffusion assay}

\section{Direct contact}

The agar disc diffusion method described by Adukwu et al. (2016) was used for determination of the antifungal properties of CEOs. Miconazole (Sigma, USA) with the concentration at $10 \mu \mathrm{g} / \mathrm{mL}$ dissolved in DMSO (Sigma) was used as the reference antifungal drug. Briefly, $100 \mu \mathrm{L}$ of yeast suspension was spread onto SDA plates and then paper discs (6 mm, Sigma) impregnated with $10 \mu \mathrm{L}$ of essential oils or dissolved miconazole were placed over the agar surface, and plates were incubated at $30^{\circ} \mathrm{C}$ for $48 \mathrm{~h}$. Plates with discs in the absence of any treatment were used as reference controls. The diameter of the 
resulting inhibition zone in the fungal lawn was measured in millimetres.

\section{Disc volatilisation assay}

The antifungal activity of CEOs in vapour phase was investigated using the disc volatilisation technique (Boukhatem et al. 2014). Briefly, $100 \mu \mathrm{L}$ of yeast suspension was spread onto SDA plates and then paper discs (6 mm, Sigma) impregnated with $10 \mu \mathrm{L}$ of essential oils or dissolved miconazole were placed on the inside surface of the upper lid. The plate was sealed with parafilm to prevent leakage of the vapour and was promptly inverted on top of the lid. Plates were incubated at $30{ }^{\circ} \mathrm{C}$ for $48 \mathrm{~h}$, and the diameter of the zone of inhibition was recorded in millimetres.

\section{Determination of minimum inhibitory concentration and minimum fungicidal concentration using broth dilution method}

The method used in this study for determination of minimum inhibitory concentration (MIC) and minimum fungicidal concentration (MFC) of CEOs was adapted from Adukwu et al. (2012) with slight modifications. Briefly, Sabouraud Dextrose broth (SDB, Oxoid Ltd., UK) was prepared with a $0.5 \%(v / v)$ concentration of Tween 20 (Sigma, USA), used as the EO emulsifier. Both CBEO and CLEO were diluted twofold into SDB with Tween 20 to create a concentration range between 4 and $0.03 \%(v / v)$. The amount of $180 \mu \mathrm{L}$ of the diluted CEOs was transferred into the corresponding wells of a 96-well microdilution plate with $20 \mu \mathrm{L}$ of yeast suspension. Microplate wells of EO dilutions without yeast, and SDB and yeast suspension, were used as negative controls, and the plates incubated at $30^{\circ} \mathrm{C}$ for $48 \mathrm{~h}$. After the appropriate incubation time, the optical density (OD) of each well was recorded at $595 \mathrm{~nm}$ using the microplate reader (infinteF200Pro, Tecan, Switzerland). The MIC was defined as the lowest $\mathrm{CEO}$ concentration that produced inhibition of yeast growth.

MFC was measured by transferring $20 \mu \mathrm{L}$ from each treated well of CEO concentration from $4 \%(v / v)$ to $0.03 \%(v / v)$ to labelled SDA plates followed by incubation at $30^{\circ} \mathrm{C}$ for $48 \mathrm{~h}$. The MFC was defined as the lowest CEO concentration that inhibited growth of the yeast or permitted less than three CFUs to occur, resulting thus in $99.9 \%$ fungicidal activity (Espinel-Ingroff et al. 2002).

\section{Effect of CEOs on the micromorphology of $C$. albicans and $C$. auris}

To investigate changes in morphology caused by exposure to the CEOs against $C$. albicans and $C$. auris, we adapted the methods of Leite et al. (2014) with some modofications. One hundred microlitres $(100 \mu \mathrm{L})$ of yeast suspension was spread onto cornmeal agar plates and then paper discs (6 $\mathrm{mm}$, Sigma) were impregnated with $10 \mu \mathrm{L}$ of essential oils and placed over the agar surface and the plates incubated at $30{ }^{\circ} \mathrm{C}$ for $48 \mathrm{~h}$. Agar plates with discs without any treatments were used as reference controls. Plates were then visualised using the light microscope (Olympus, UK), tenfold magnification. Following incubation, two to three fungal colonies at the edge of the inhibitory zone were gently removed and placed on a clean microscope slide. A drop of Lacto-Fuchsin stain was placed on the sample and covered by a coverslip. The slides were examined under light microscope with 40-fold magnification.

\section{Modulation of cell membrane permeability}

To assess the integrity of the yeast cell membranes following treatment with the CEO exposure, the cellular content leakage assay method described by Khan et al. (2013) was adapted with some modifications. Briefly, $200 \mu \mathrm{L}$ of cell suspensions were transferred to wells of the 24-well plates (SLS, UK) containing $1800 \mu \mathrm{L}$ of diluted CEOs at different concentrations $(0.03,0.015$ and $0.008 \%(v / v)$ for CBEO; 0.13, 0.06 and $0.03 \%(v / v)$ for CLEO). CEOs in PBS served as blank, untreated cells in PBS as controls. Plates were incubated at $30^{\circ} \mathrm{C}$ for $24 \mathrm{~h}$. After the incubation period, the samples were centrifuged (1250 rpm, $2 \mathrm{~min}$ ) and the release of cellular material in the supernatants was determined by using spectrophotometric measurement of cell supernatant at 260/280 nm (corresponding to nucleic acids and proteins).

\section{Scanning electron microscopy}

Three sets of samples of the test strains were prepared with treatments at 0.03 and $0.015 \%(v / v)$ for CBEO and 0.13 and $0.06 \%(v / v)$ for CLEO. Control samples which consisted of the organisms without any treatment were also prepared. Fungal cultures were grown for $48 \mathrm{~h}$ in SDB, and $100 \mu \mathrm{L}$ of the samples were dropped onto sterile metal discs and incubated for $48 \mathrm{~h}$ at $30{ }^{\circ} \mathrm{C}$ to establish fungal growth. The samples were then fixed using glutaraldehyde fixative. Periodic hourly rinsing of the samples three times with $\mathrm{PBS}$ was required to minimize any activity of the CEOs and to allow for clearing of any debris, which could affect the viewing of the samples. After that, samples were dehydrated using ethanol at different concentrations from 20 to $100 \%(v / v)$ and hexamethyldisilazane. Samples were then air dried, gold coated and visualized using the FEI Quanta FEG 650 SEM (Thermo Fisher Scientific, USA). 


\section{Assessment of Haemolytic activity}

\section{Haemolytic activities of Candida strains and CEOs}

To determine haemolytic activity of the Candida isolates, SDA medium containing 7\% $(v / v)$ horse blood (TCS Biosciences Ltd. UK) with or without $3 \%(w / v)$ glucose was used. A $10-\mu \mathrm{L}$ yeast suspension or diluted CEOs at different concentrations from $4 \%(v / v)$ to $0.03 \%(v / v)$ was inoculated onto plates in triplicate; these were then incubated at $37^{\circ} \mathrm{C}$ for $24 \mathrm{~h}$ in aerobic condition. After incubation, a transparent/ semi-transparent zone around the inoculation site was considered positive haemolytic activity. The ratio of the diameter of the colony to that of the translucent zone of haemolysis ( $\mathrm{mm}$ ) was used as the haemolytic index, as described by Wan et al. (2015).

\section{Effect of CEOs on the haemolytic activity of Candida isolates}

The inhibition of haemolysin production in tested strains was conducted using the method of Manns et al. (1994) with some modifications. Briefly, Candida isolates were grown in SDB with $8 \%(v / v)$ glucose and CBEO at final concentrations of $0.03,0.015$ and $0.008 \%(v / v)$ and CLEO at final concentrations of $0.13,0.06$ and $0.03 \%(v / v)$ and incubated at $37^{\circ} \mathrm{C}$ for 48 h. The SDB without CEOs was used as a control. The supernatant was collected from the incubated broth cultures by centrifuging at $5000 \mathrm{rpm}$ for $30 \mathrm{~min}$. Freshly washed sterile RBCs from horse blood (TCS Biosciences Ltd. UK) suspended in sterile PBS and enriched with $5 \%(w / v)$ glucose were mixed in a ratio of $1: 1$ with the supernatant and incubated at $37^{\circ} \mathrm{C}$ for $3 \mathrm{~h}$. Tubes were centrifuged at $2000 \mathrm{rpm}$ for $10 \mathrm{~min}$ and read at $540 \mathrm{~nm}$. Mean absorbance values were used to calculate the reduction percentage in the production of haemolysin in treated samples over untreated controls.

\section{Results}

\section{Analysis of chemical composition (GC-MS)}

The qualitative and quantitative composition of the used CBEO and CLEO is shown in Table 1. The number of identified components was greater in CLEO representing approximately $93 \%$ of the entire EO than the CBEO representing approximately 95\%. The CLEO was characterized by high amounts of eugenol at $62.57 \%$ whilst in the CBEO this component was only $5.28 \%$. The main component of CBEO was trans-cinnamaldehyde $(66.43 \%)$ with $<2 \%$ of this compound identified in the CLEO.

\section{Antifungal susceptibility screening}

Results from the antifungal susceptibility tests are summarized in Table 2. Both CBEO and CLEO demonstrated stronger antifungal activity against tested strains when compared with miconazole - an antifungal drug that is typically used in treatment of skin infections including those caused by yeast, e.g. candidiasis. The CBEO demonstrated greater inhibitory activity against $C$. albicans and $C$. auris in comparison with CLEO in the direct disk diffusion and disk volatilisation assays (Table 2). The CBEO was approximately twice as effective as the CLEO (direct contact) and approximately between 2 to 3.5 times more effective than CLEO (vapour assay).

\section{Inhibitory and fungicidal activity}

Results in Table 3 showed that $C$. albicans and $C$. auris were susceptible to CBEO and CLEO at low concentrations with both yeast species exhibiting greater susceptibility to $\mathrm{CBEO}$ with MIC and MFC activity observed at concentrations below $0.03 \%(v / v)$. The inhibitory action of CLEO against the Candida spp. at low concentrations between 0.06 and $0.13 \%$ $(v / v)$ was effective at inhibiting the growth of C. albicans and $C$. auris strains; however, fungicidal activity of CLEO was observed at $0.25 \%(v / v)$.

\section{Effect of CEOs on the micromorphology of $C$. albicans and $C$. auris}

Results from the cornmeal agar assay showed that the C. albicans strains were predominantly comprised of filaments and after exposure to the EOs, hyphae formation was noticeably reduced in both $C$. albicans strains, especially $C$. albicans ATCC 2091. No change in morphology in the $C$. auris isolate was observed before and after exposure to both CEOs.

\section{Actions of CEOs on cell membrane permeability}

The mechanism of action of CBEO and CLEO on C. albicans and $C$. auris was determined by cellular content leakage assay and scanning electron microscopy (SEM) morphological analysis following treatment with both CBEO and CLEO. The cellular content leakage assay shows that the envelop of the Candida spp. under investigation was damaged by the CEOs, demonstrated by the nucleic acid and protein release, i.e. cell lysis (Figs. 1 and 2). These results were supported by SEM images, which revealed receding of the cell membrane and shrinkage of cell surfaces (Fig. 3).

In the cell content leakage assay, an increase in $\mathrm{OD}_{260 \mathrm{~nm}}$ indicates a release of nucleic acid whilst the $\mathrm{OD}_{280 \mathrm{~nm}}$ shows protein release. Following exposure of the test organisms to CBEO, nucleic acid and protein release were observed $(p<0.05)$. In addition, the higher the concentration, the 
Table 1 GC-MS analysis of CBEO and CLEO showing major components

\begin{tabular}{lll}
\hline Components & Cinnamon leaf (\%) & Cinnamon bark (\%) \\
\hline Bicyclo [3.1.1] hept-2-ene, 3,6,6-trimethyl- & 2.54 & - \\
Alpha-Phellandrene & 2.27 & - \\
Benzene, 1-methyl-4-(1-methylethyl)- & 1.7 & - \\
Cyclohexene, 1-methyl-5-(1-methylethenyl)-, (R)- & 1.43 & - \\
1,6-Octadien-3-ol, 3,7-dimethyl- & 3.79 & 7.61 \\
Eugenol & 62.57 & 5.28 \\
Caryophyllene & 4.17 & - \\
Benzyl benzoate & 4.09 & 2.86 \\
Phenol, 2-methoxy-4-(2-propenyl)-, acetate & 3.49 & - \\
trans-Cinnamaldehyde & 1.92 & 66.43 \\
1,3-Benzodioxole, 5-(2-propenyl)- & 1.73 & - \\
2-Propen-1-ol, 3-phenyl-, acetate & 2.3 & - \\
Eucalyptol & 0.33 & 6.63 \\
Butane, 2-methyl- & - & 4.74 \\
Benzaldehyde & 0.27 & 1.04 \\
Percentage of total components in the EO & 92.6 & 94.59 \\
\hline
\end{tabular}

greater the nucleic acid and protein leakage. Figure 2 also demonstrates cell content leakage following exposure to CLEO at the MIC and concentrations below the MIC; however, the cell content leakage was not significantly different $(p>0.05)$ from the untreated samples at 0.06 and $0.03 \%(v / v)$.

The MIC and MFC of CBEO were found to be below the test concentration range $<0.03 \%(v / v)$ and at $0.015 \%(v / v)$; the three test organisms were damaged and had lost turgidity and integrity when exposed to these concentrations (observed by SEM). C. albicans ATCC 2091 and C. auris NCPF 8971 were killed at $0.13 \%(v / v)$ of CLEO while the control cells appeared turgid and whole with smooth cell membrane (Fig. 3a-c). Figure 3 (m-o) shows some undamaged cells when the cells were exposed to CLEO at $0.06 \%(v / v$; MIC for C. albicans ATCC 2091 and $C$. auris NCPF 8971) which is a confirmation of fungistatic activity at that concentration and at $0.13 \%$ $(v / v)$, the cells were damaged by the CLEO.

\section{Haemolysin activities of Candida isolates}

In the glucose-enriched agar plates, two different types of haemolysis were observed circumscribing the yeast "colony" when viewed with transmitted light. The first was a totally translucent ring identical to beta-haemolysis, and the second was a greenish-black halo comparable with alpha-haemolysis. At $24 \mathrm{~h}$ incubation, only alpha-haemolysis was observed in the glucose-free plates. However, after $48 \mathrm{~h}$ incubation, only beta-rings were observed in glucose-free plates. We clearly observed greater haemolytic activity in the three tested strains in the glucose-enriched plates compared with the glucose-free plates.

Results in Table 4 show the haemolysin activities of Candida isolates. In both glucose-enriched and glucose-free plates, haemolysis activity was higher in C. albicans ATCC 10231 with the mean diameters of alpha- and beta-rings in

Table 2 Inhibitory zones (mm) of fungal growth in C. albicans and C. auris by bark CEO, leaf CEO and miconazole $(10 \mu \mathrm{g} / \mathrm{mL})$ after $48 \mathrm{~h} \mathrm{of}$ incubation

\begin{tabular}{|c|c|c|c|c|c|c|c|}
\hline \multirow[t]{2}{*}{ Selected yeasts } & \multirow[t]{2}{*}{ Mode of exposure or treatment } & \multicolumn{2}{|l|}{ Bark CEO } & \multicolumn{2}{|l|}{ Leaf CEO } & \multicolumn{2}{|l|}{ Miconazole } \\
\hline & & Mean (mm) & SE & Mean $(\mathrm{mm})$ & SE & Mean $(\mathrm{mm})$ & SE \\
\hline C. albicans ATCC 10231 & & 53.00 & 1.68 & 26.32 & 0.67 & 24.33 & 1.37 \\
\hline C. albicans ATCC 2091 & Direct contact & 56.68 & 0.85 & 30.17 & 0.76 & 31.33 & 0.97 \\
\hline C. auris NCPF 8971 & & 70.40 & 1.53 & 39.67 & 1.00 & 32.82 & 0.39 \\
\hline C. albicans ATCC 10231 & & 55.52 & 0.65 & 15.08 & 0.82 & NA & NA \\
\hline C. albicans ATCC 2091 & Vapour exposure & 59.72 & 1.07 & 18.90 & 0.33 & NA & NA \\
\hline C. auris NCPF 8971 & & 77.37 & 1.72 & 35.40 & 1.08 & NA & NA \\
\hline
\end{tabular}

Results were from three independent experiments performed in triplicate $(N=3)$ 
Table 3 The antifungal activity of bark and leaf CEO (MICs and MFCs) against $C$. albicans and C. auris

\begin{tabular}{llllll}
\hline Selected yeasts & \multicolumn{3}{l}{ Bark CEO } & & \multicolumn{2}{l}{ Leaf CEO } \\
\cline { 2 - 3 } \cline { 5 - 6 } & MIC \% $(v / v)$ & MFC \% $(v / v)$ & & MIC \% $(v / v)$ & MFC \% $(v / v)$ \\
\hline C. albicans ATCC 10231 & $<0.03$ & $<0.03$ & 0.13 & 0.25 \\
C. albicans ATCC 2091 & $<0.03$ & $<0.03$ & & 0.06 & 0.25 \\
C. auris NCPF 8971 & $<0.03$ & $<0.03$ & & 0.06 & 0.25 \\
\hline
\end{tabular}

Results were from three independent experiments performed in triplicate $(N=3)$ glucose-enriched plates after $24 \mathrm{~h}$ incubation being $15.51 \pm$ 0.36 and $21.46 \pm 0.6 \mathrm{~mm}$, respectively. Meanwhile, in the glucose-free agar plates, the mean diameter of alpha-rings of C. albicans ATCC 10231 was $11.42 \pm 0.31 \mathrm{~mm}$. After $48 \mathrm{~h}$ incubation, the mean diameters of alpha- and beta-rings of C. albicans ATCC 10231 in glucose-added plates were still the highest among three tested stains. The mean diameter of beta-rings of C. albicans ATCC 10231 in glucose-free plates was $16.63 \pm 0.41 \mathrm{~mm}$. In contrast, haemolysis was lower in C. auris NCPF 8971 with mean alpha- and beta-rings in glucose-enriched plates after $24 \mathrm{~h}$ incubation were $10.61 \pm$ 0.4 and $16.43 \pm 0.43 \mathrm{~mm}$, respectively. After $48 \mathrm{~h}$ incubation, the mean diameter of beta-rings of $C$. auris NCPF 8971 in glucose-free plates was $14.56 \pm 0.23 \mathrm{~mm}$.

\section{Effects of bark and leaf CEOs on the haemolytic activity of $C$. albicans and $C$. auris}

An antifungal agent may either increase or attenuate the virulence factors released by fungal cells (Khan and Ahmad, 2013). Clinical performance of an antifungal compound is not only determined by its fungicidal or fungistatic activity but also by its influence on virulence factor release (Lopes et al. 2013). To ensure that the CEO concentration in this test was not directly responsible for the haemolytic activity following the challenge with the yeast species under investigation, assays to test the haemolysis activity of CBEO and CLEO were conducted on horse blood agar (Fig. 4). The results indicated that both CEOs could cause haemolytic activity at high concentration; however, at concentrations $\leq 1 \%(v / v)$ for CBEO and $<0.5 \%(v / v)$ for CLEO, both CEOs did not cause any haemolytic activity in vitro.

The results from the inhibitory effects of CBEO and CLEO on the haemolytic activity of $C$. albicans and $C$. auris are presented in Fig. 5. Following treatment with both CEOs at different concentrations, haemolytic activity was reduced in all tested organisms. CBEO at $0.03 \%(v / v)$ and $0.015 \%(v / v)$ reduced haemolysis in the tested strains to lower than $20 \%$ overall and at $0.008 \%(v / v)$ haemolysis was reduced by approximately $30 \%$ (Fig. 5a). At the same concentration, haemolysis was reduced by over $80 \%$. CLEO also reduced haemolytic activity of $C$. albicans and $C$. auris at the MIC and the concentration $2 \times$ MIC (Fig. 5b). At the sub-inhibitory concentration, $0.5 \times \mathrm{MIC}$, there was no significant difference between the treated and untreated strain $(C$. albicans ATCC $10231 ; p>0.05)$.

\section{Discussion}

\section{Analysis of chemical composition (GC-MS)}

The GC-MS results in this study were similar to that of Mayaud et al. (2008) with the exception of cinnamaldehyde, which was not found in the CLEO, analysed in their paper. Previous studies have shown that both trans-cinnamaldehyde and eugenol, the key components of CBEO and CLEO, respectively have been are antimicrobial against bacteria and fungi. In a recent review article by Doyle and Stephens (2019), trans-cinnamaldehyde was found to be responsible for causing damage to the bacterial cells via different methods; cell release activity, anti-quorum sensing activity, effect on ATP etc. Eugenol, on the other hand, has been shown to cause morphological changes and damage to Candida albicans-adherent cells and biofilms (He et al. 2007). To our knowledge, very little is known on the effects of EOs against the new pathogen $C$. auris and there are no published reports on the effects of CEOs against this pathogen.

\section{Antifungal activity of CBEO and CLEO}

The susceptibility of $C$. albicans and $C$. auris to the antifungal effects of bark and leaf CEO when in contact with the fungal lawns and in vapour phase was determined. The results were consistent with the studies by Brnawi et al. (2018) and Ranasinghe et al. (2002) who found CBEO to be a more effective antimicrobial than CLEO. Research into the antimicrobial vapour investigations using EOs is gaining interest, and our results further support this with CBEO demonstrating strong antimicrobial activity in vapour phase while CLEO produces major inhibition in direct contact. The main component of CBEO is trans-cinnamaldehyde and that of CLEO is eugenol. The study by Sanla-Ead et al. (2012) investigated the antifungal activity of trans-cinnamaldehyde and eugenol and 


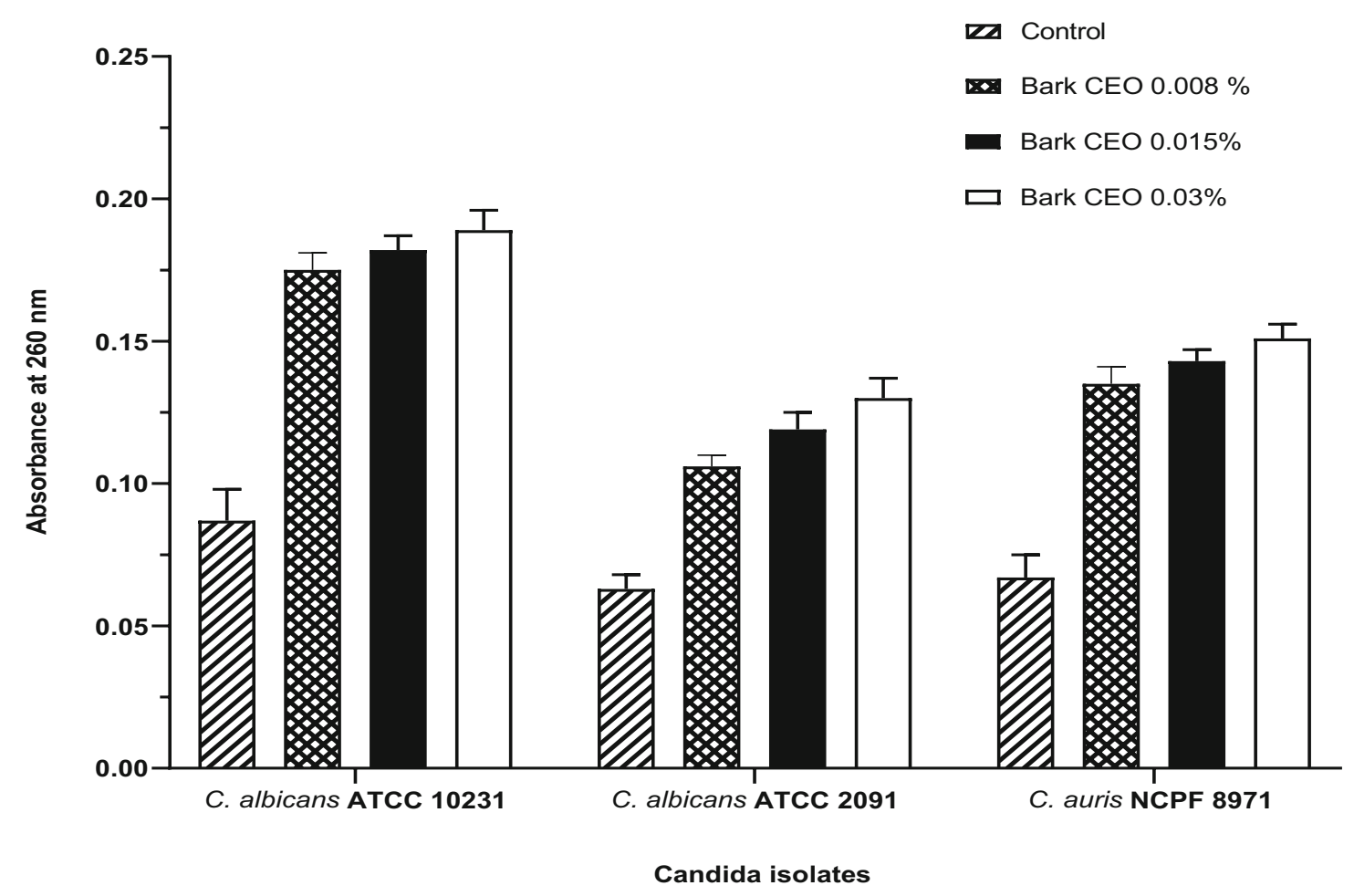

(a)

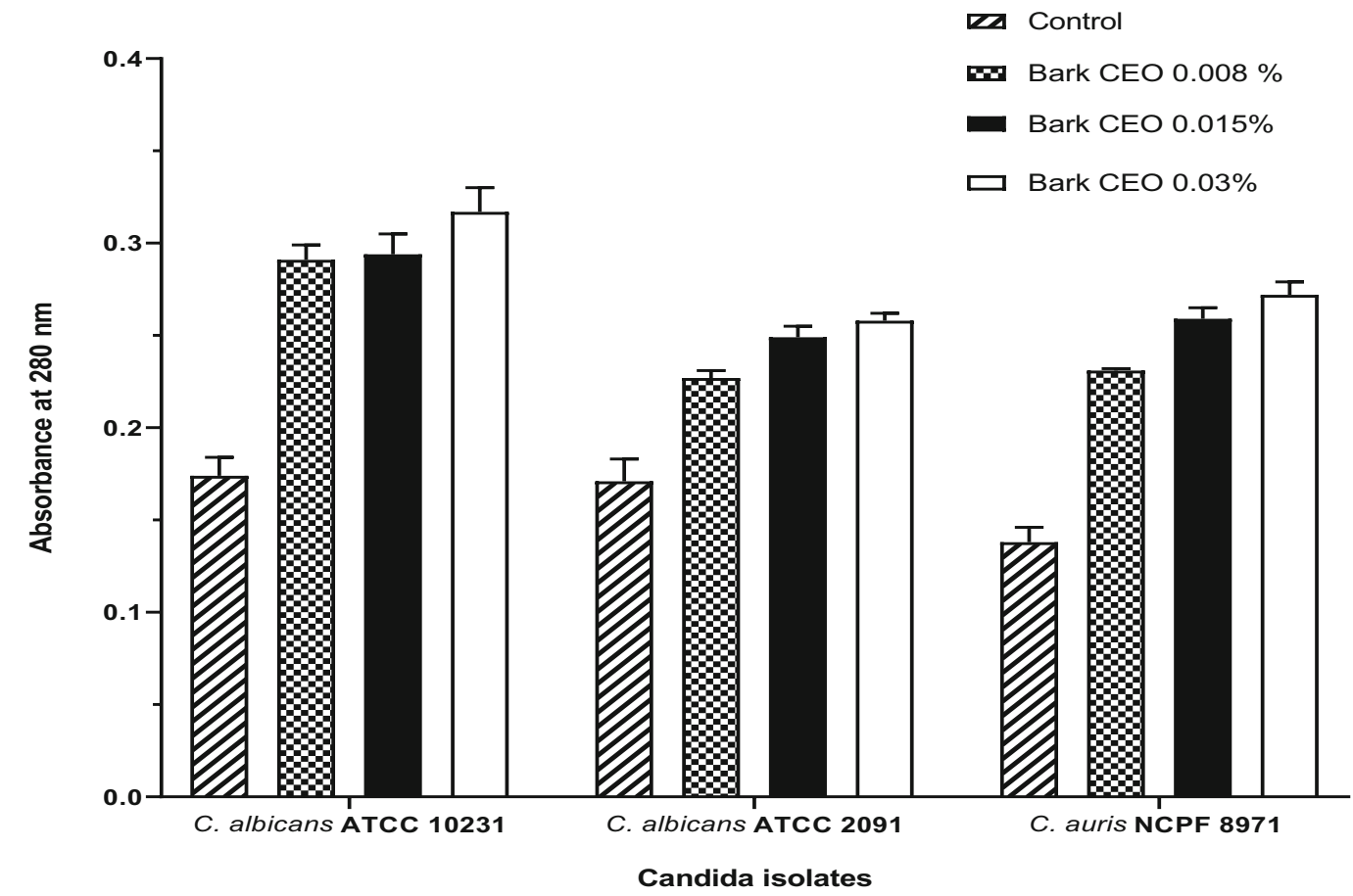

(b)

Fig. 1 Assessment of (a) nucleic acid release, $\mathrm{OD}_{260 \mathrm{~nm}}$ and (b) protein release $\mathrm{OD}_{280 \mathrm{~nm}}$ from C. albicans and $C$. auris after treatment with cinnamon bark essential oil at $0.008,0.015$ and $0.03 \%(v / v)$. This

found that trans-cinnamaldehyde displayed stronger antifungal activity in vapour phase which might explain why CBEO experiment was carried out on three separate occasions $(N=3)$ with the bars showing mean values $( \pm \mathrm{SE})$

was more effective in vapour phase when compared with CLEO. Antimicrobial activity via vapour diffusion offers a 


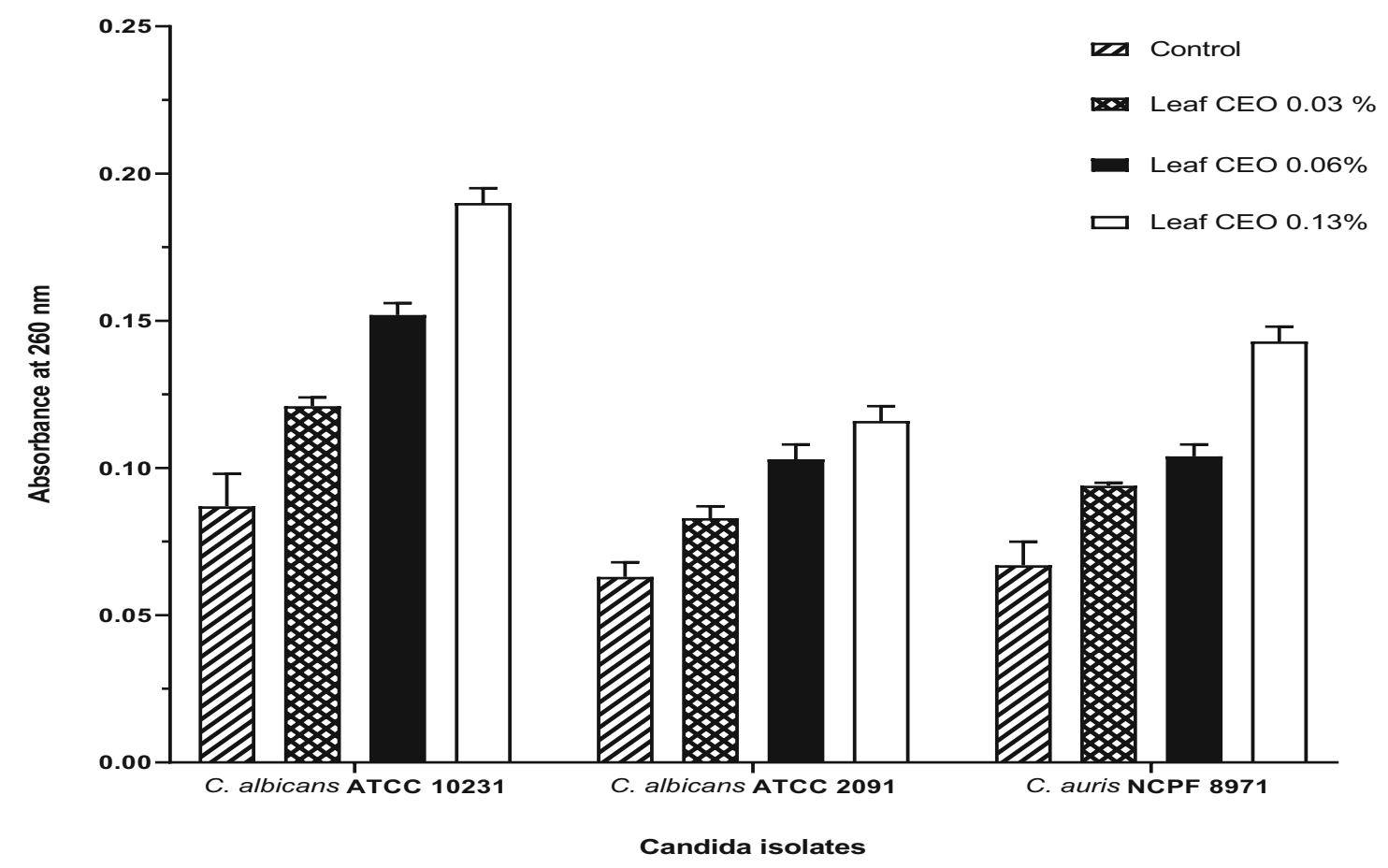

(a)

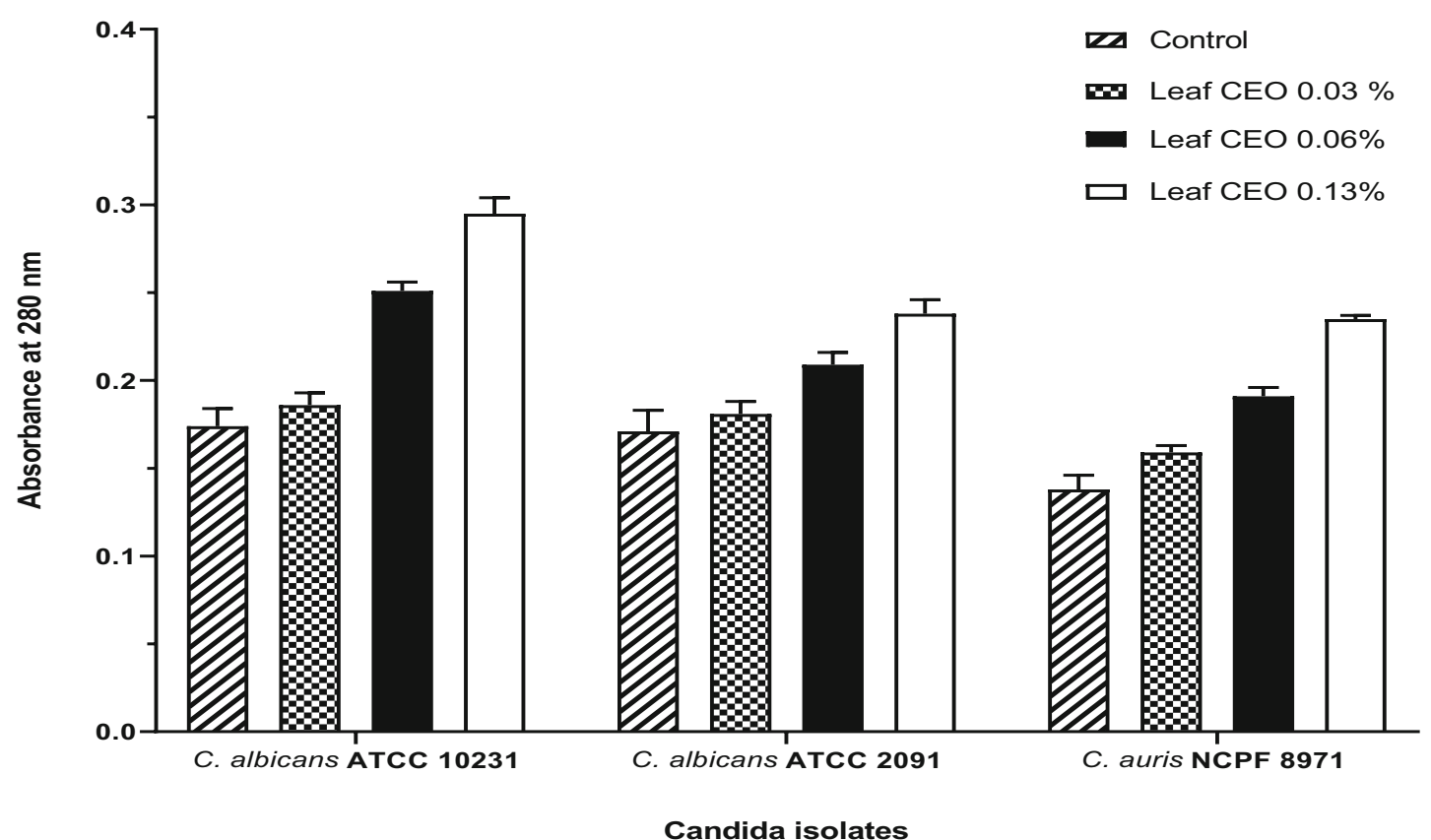

Fig. 2 Assessment of (a) nucleic acid release, $\mathrm{OD}_{260 \mathrm{~nm}}$ and (b) protein release $\mathrm{OD}_{280 \mathrm{~nm}}$ from $C$. albicans and $C$. auris after treatment with cinnamon leaf essential oil at $0.03,0.06$ and $0.13 \%(v / v)$. This

different delivery mode for the CEOs and other essential oils for the treatment and management of infections, e.g. in clinical settings to improve air quality by means of decontamination.

Both CBEO and CLEO demonstrated fungicidal properties at very low concentrations. C. auris has been described as a experiment was carried out on three separate occasions $(N=3)$ with the bars showing mean values $( \pm \mathrm{SE})$

notorious nosocomial pathogen requiring urgent efforts to understand and to identify therapeutic options due to high transmissibility, challenges with identification, incorrect use of antifungal drugs and treatment failures, which lead to high mortality (Sears and Schwartz 2017; Sardi et al. 2018). The 

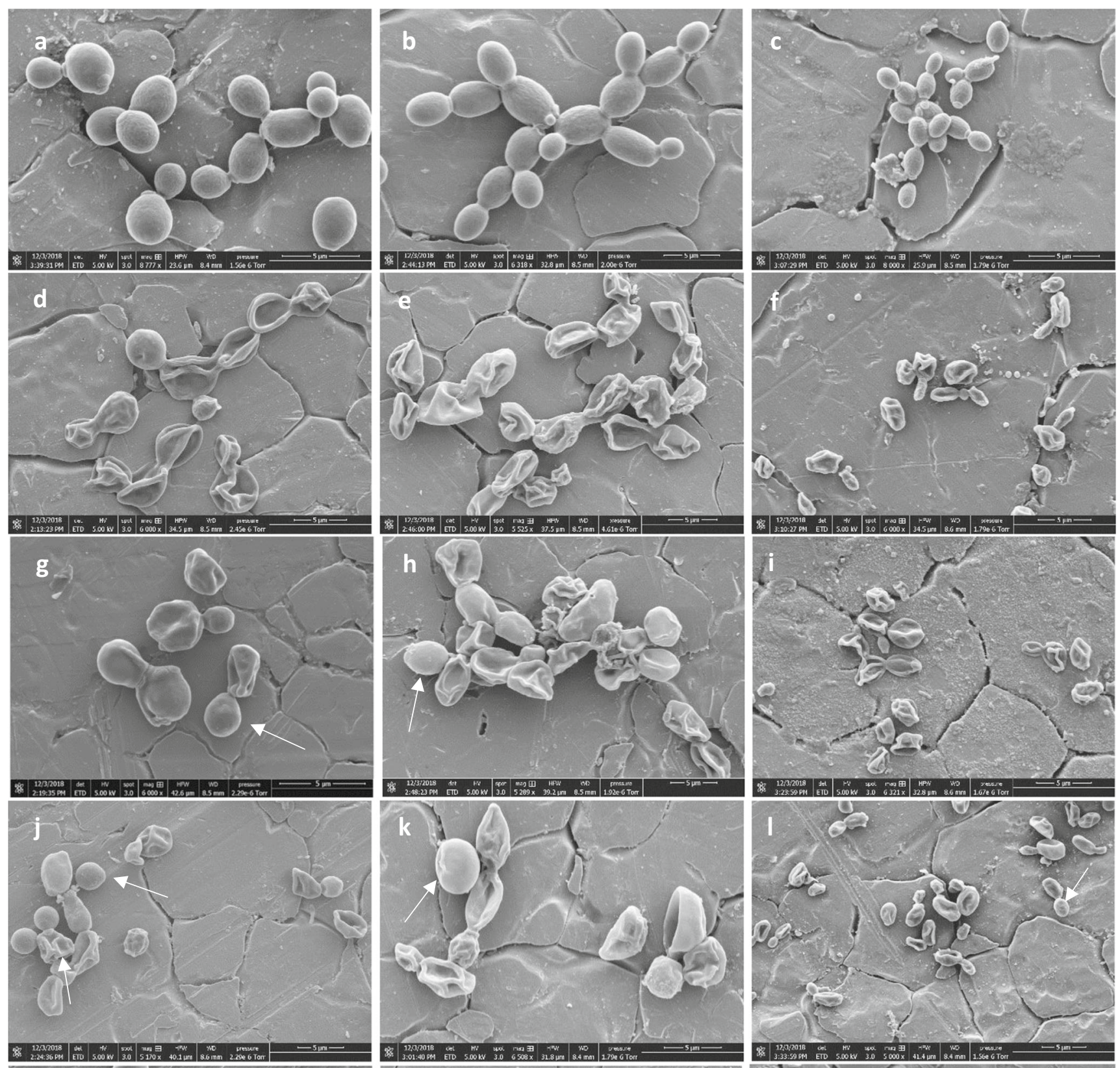

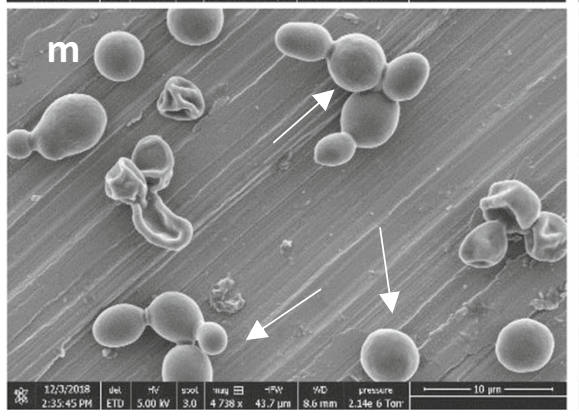

Column 1: SEM of

C. albicans ATCC 10231

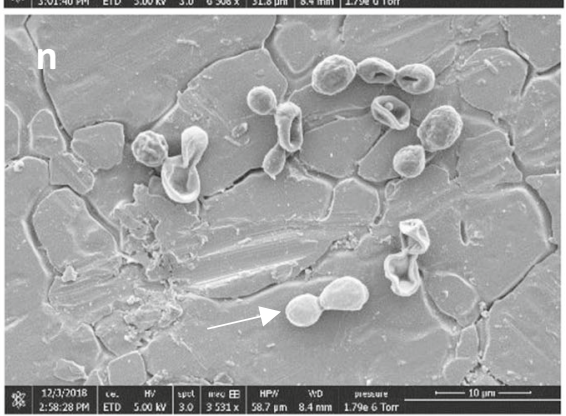

Column 2: SEM of

C. albicans ATCC 2091

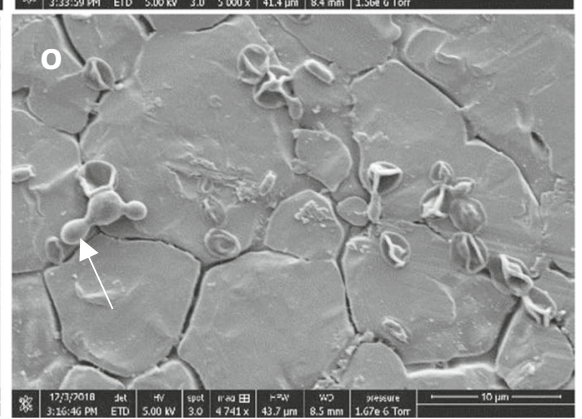

Column 3: SEM of C. auris NCPF 8971
Fig. 3 Scanning electron microphotographs of C. albicans ATCC 10231 (column 1), C. albicans ATCC 2091 (column 2) and C. auris NCPF 8971 (column 3). (a-c) Untreated cells; $(\mathbf{d}-\mathbf{f})$ Bark CEO $0.03 \%(v / v)$ treated cells; (g-i) Bark CEO $0.015 \%(v / v)$ treated cells; (j-l) leaf CEO $0.13 \%(v /$ $v$ treated cells; $(\mathbf{m}-\mathbf{0})$ The white arrows indicate fungal cells which are undamaged or having a minor damage under treatments. Magnification, $\times$ 5000 
Table 4 Diameters of $\alpha$ - and $\beta$-rings (mm) representing haemolytic activity of C. albicans ATCC 10231, C. albicans ATCC 2091 and C. auris NCPF 8971 with and without glucose enrichment after incubation for 24 and $48 \mathrm{~h}$

\begin{tabular}{|c|c|c|c|c|}
\hline Organisms & Glucose conc. $(w / v)$ & Incubation time $(\mathrm{h})$ & $\alpha$-Ring (mm) & $\beta$-Ring (mm) \\
\hline \multirow[t]{4}{*}{ Candida albicans ATCC 10231} & 3 & \multirow[t]{2}{*}{24} & $15.51( \pm 0.36)$ & $21.46( \pm 0.60)$ \\
\hline & 0 & & $11.42( \pm 0.31)$ & 0 (non-haemolytic) \\
\hline & 3 & \multirow[t]{2}{*}{48} & $17.72( \pm 0.15)$ & $28.83( \pm 0.46)$ \\
\hline & 0 & & 0 (non-haemolytic) & $16.63( \pm 0.41)$ \\
\hline \multirow[t]{4}{*}{ Candida albicans ATCC 2091} & 3 & \multirow[t]{2}{*}{24} & $14.26( \pm 0.33)$ & $20.7( \pm 0.43)$ \\
\hline & 0 & & $10.96( \pm 0.27)$ & 0 (non-haemolytic) \\
\hline & 3 & \multirow[t]{2}{*}{48} & $17.7( \pm 0.35)$ & $26.2( \pm 0.75)$ \\
\hline & 0 & & 0 (non-haemolytic) & $16.38( \pm 0.37)$ \\
\hline \multirow[t]{4}{*}{ Candida auris NCPF 8971} & 3 & \multirow[t]{2}{*}{24} & $10.61( \pm 0.40)$ & $16.43( \pm 0.43)$ \\
\hline & 0 & & $9.7( \pm 0.16)$ & 0 (non-haemolytic) \\
\hline & 3 & \multirow[t]{2}{*}{48} & $15.11( \pm 0.36)$ & $24.54( \pm 0.43)$ \\
\hline & 0 & & 0 (non-haemolytic) & $14.56( \pm 0.23)$ \\
\hline
\end{tabular}

Results were from three independent experiments performed in triplicate $(N=3)$

limited antifungal treatment options for this important pathogen creates a need to develop new alternative treatments in line with the global antimicrobial resistance strategies, which indicates the development of new treatments and reduce reliance on existing conventional antimicrobials as an important step.
Fig. 4 Photographs depicting the hemolysis of horse blood agar (supplemented with $3 \% \mathrm{w} / \mathrm{v}$ of glucose) induced by different concentrations of bark $\mathrm{CEO}(1,2)$ and leaf $\operatorname{CEO}(3,4)$. Panel a shows pure bark CEO (a) and pure leaf CEO $(\mathrm{k})$ served as positive control; Sabouraud dextrose broth $+0.5 \%$ Tween 20 served as negative control (j); bark CEO $4 \%$ (b); bark CEO 2\% (c); bark CEO $1 \%$ (d); bark CEO $0.5 \%$ (e); bark CEO $0.25 \%$ (f); bark CEO $0.125 \%(\mathrm{~g})$; bark CEO $0.06 \%(\mathrm{~h})$; bark $0.03 \%$ (i); leaf CEO $4 \%$ (1); leaf CEO $2 \%(\mathrm{~m})$; leaf CEO $1 \%$ (n); leaf CEO 0.5\% (o); leaf CEO $0.25 \%$ (p); leaf CEO $0.125 \%$ (q); leafCEO $0.06 \%$ (r); and leaf CEO $0.03 \%$ (s)
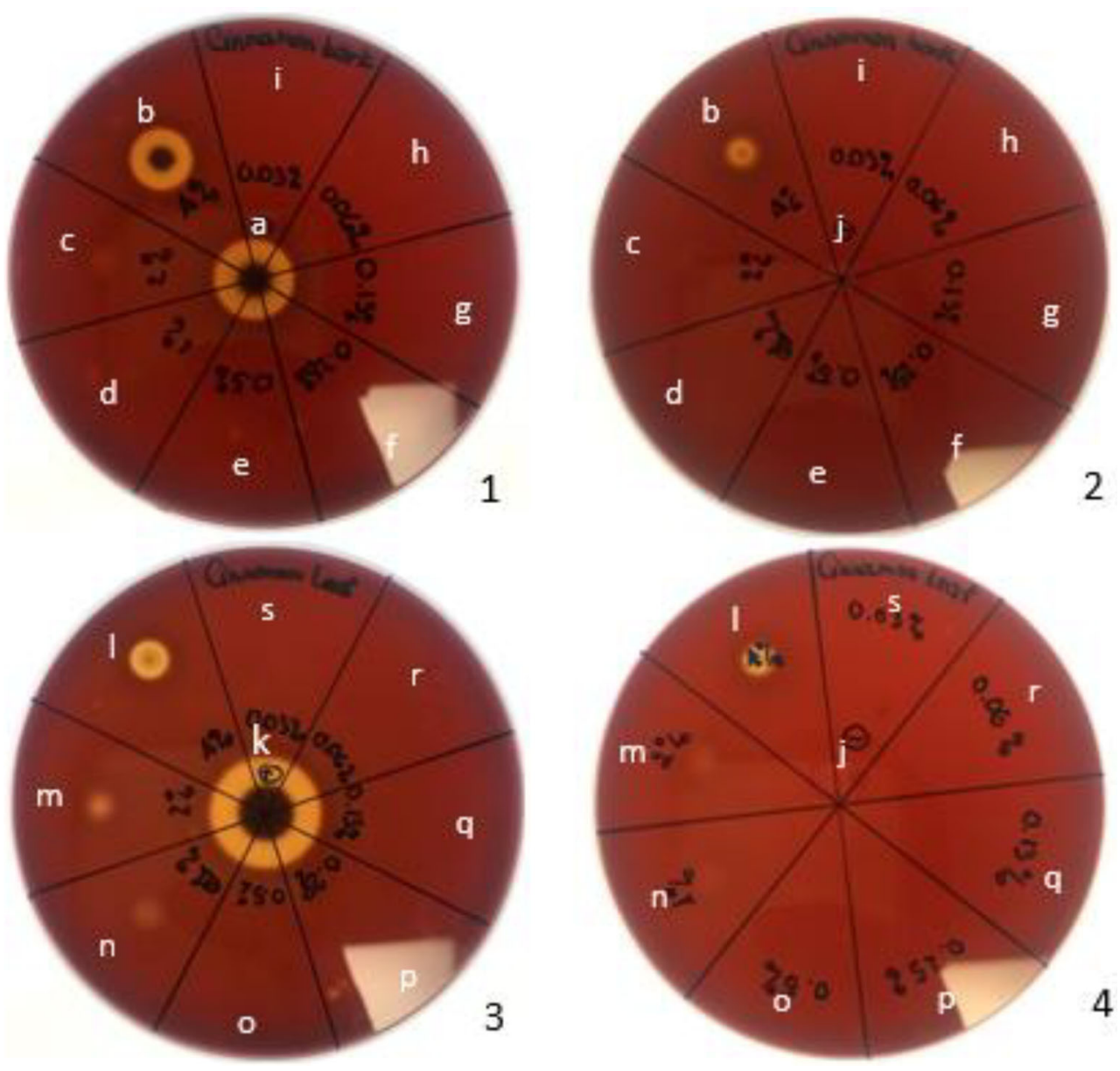

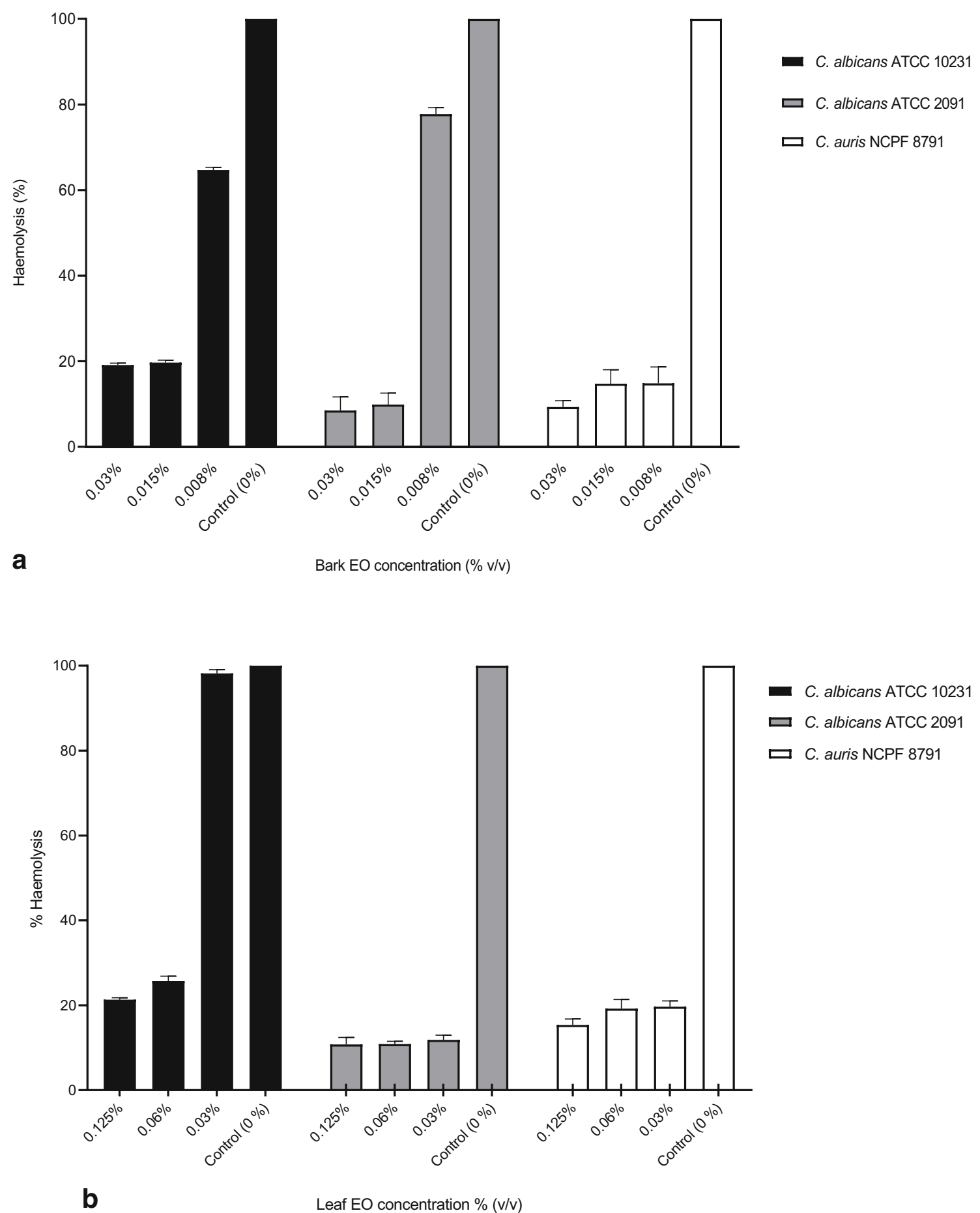

Fig. 5 Effects of CBEO (a) and CLEO (b) at different concentrations on the inhibition of haemolysis in C. albicans ATCC 10231; C. albicans ATCC 2091 and C. auris NCPF 8971. This experiment was carried out

\section{Effect of CEOs on the micromorphology of C. albicans and $C$. auris}

Germination is considered one of the major virulence factors known to contribute to Candida pathogenesis (Larkin et al. 2017). In C. albicans, virulence gene expression is linked to on three separate occasions and in triplicate $(N=3)$ with the bars showing mean values $( \pm \mathrm{SE})$

its ability to transition from yeast form to hyphal form (Gow et al. 2002). The yeast-to-hyphal transition in C. albicans is known to promote virulence because hyphae can exert mechanical force to breach and damage endothelial cells (Thompson et al. 2011). Moreover, macrophages and neutrophils can be lysed by the growth of C. albicans hyphae (Lo 
et al. 1997). In the presence of CEOs, hyphal formation was inhibited in the $C$. albicans strain ATCC 2091, suggesting a potential mechanism of action of the $\mathrm{EO}$ as hyphae formation is associated with release of virulence factors. The findings also showed that under similar test conditions, C. auris NCPF 8971 did not germinate, form hyphae or produce chlamydospores. Since the ability of Candida to invade endothelial cells is important in causing candidemia and candidiasis, the inability to form hyphae of $C$. auris NCPF 8971 suggests that virulence as described in other studies is likely as a result of other factors and requires further investigation.

\section{Actions of CEOs on cell membrane permeability}

The mechanism of action of CBEO and CLEO on C. albicans and $C$. auris was damage to the envelop, evident by the shrinkage of the cell surfaces and receding of cytoplasm leading to lysis of cells. In addition, the level of membrane damages of Candida cells correlated with the concentration of CEOs used. This finding suggests that the membrane-destructive action of both CBEO and CLEO depends on the concentration of oils. This conclusion was re-confirmed by the increase in the level of nucleotide and protein in the extracellular media. Khan et al. (2013) proposed that membranous structures such as cell wall and cell membrane of fungal cells are the target sites of transcinnamaldehyde and eugenol. This activity, in part, can be due to lipophilic properties of these compounds for their partition into the lipid bilayer of the plasma membrane (Knobloch et al. 1989), leading to the disruption of the structure of different membrane layers and subsequently permeability. Another study by Shahina et al. (2018) using utilizing atomic force microscopy (AFM) imaging, laser scanning confocal Microscopy (LSCM) imaging and Congo red staining techniques, demonstrated cell surface exfoliation, altered ultrastructure, delayed cell cycle and reduced cell wall integrity in $C$. albicans cells following exposure to CBEO. In their study, the findings suggested that not only cinnamaldehyde possess the ability to compromise cell membrane and wall integrity but also minor components of CBEO such as limonene, eugenyl acetate, linalool and benzyl benzoate contribute to CBEO antifungal activity by other routes of impact such as introducing spindle defect or arresting cell cycle in the anaphase. Further assays are needed to determine other sites of action of the CEOs on Candida spp., e.g. transmission electron microscopy, sorbitol protection assay or flowcytometry. However, the results from this study clearly demonstrate antifungal activity of both CBEO and CLEO against the C. albicans and for the first time, against $C$. auris. Both species of Candida irrespective of morphology switching action had significantly damaged cell membrane structures when exposed to low concentrations of the EOs.

\section{Antihaemolytic effect of CEOs}

To date, very few studies have investigated the haemolytic activity of $C$. auris although it has been shown to be a great source of nosocomial bloodstream infections (Sardi et al. 2018). Haemolytic activity has been demonstrated in several studies and is a factor in the pathogenesis of $C$. albicans (Luo et al. 2001; Favero et al. 2014). In our study, both C. albicans and $C$. auris produced haemolysis in the glucose-enriched blood media, which is of importance as haemolysis activity in the presence of glucose has been indicated as a possible factor in the pathogenesis of Candida in diabetic patients (Malcok et al. 2009). However, with the presence of CEOs, at MIC and sub-MICs, both CBEO and CLEO inhibited production of haemolysin factors in C. albicans and C. auris which offers some insight into a not well-described activity of EOs on Candida spp. supporting our initial findings from the cornmeal agar assay where switching to hyphal form was inhibited in the presence of the CEOs. In the review article by Nayak et al. (2013), there is enhanced haemolytic activity in C. albicans which is characterized by iron uptake leading to and secretion of haemolysin, facilitating hyphal invasion during candidiasis infections. Thus, the reduction of haemolytic activity, the prevention of morphology switching from spore to hyphae and damage to the membrane are demonstrated here as some of the mechanisms of action of the cinnamon EOs against the Candida species. The potential of cinnamon EO as an antifungal agent is also evident with the inhibitory and fungicidal action against $C$. albicans and $C$. auris at low concentrations of both leaf and bark oils. Both EOs were shown to be fast-acting antimicrobials against Pseudomonas aeruginosa in a recent study by Elcocks et al. (2020), and with such promising action against two troublesome pathogenic Candida species, there is a clear need to explore this EO further as a treatment option for candidiasis infections.

In summary, the findings reported here demonstrate for the first time the potential of both bark and leaf CEOs to exert antifungal activity against $C$. auris, which is a newly found Candida spp., along with C. albicans. Mode of action of these oils towards fungal cells determined by SEM analysis, highlight their ability to damage the membranous structures of fungal cells. In this study, test Candida strains and CEOs at high concentrations all showed haemolytic activities. At MIC and sub-MICs, both bark and leaf CEOs reduced the germination and haemolysin factors in C. albicans and C. auris. Further in vivo studies are needed to assess any potentially toxic effect of CEOs; however, the antifungal and antihaemolytic activity raise another interesting field in researching antifungal therapeutic interventions in both clinical and industrial applications.

Acknowledgements The authors would like to thank Dr. David Patton and Mr. Paul Bowdler from the Centre for Research in Bioscience 
laboratories at UWE Bristol for technical support with Scanning Electron Microscopy and GC-MS analysis.

Authors' contributions Hoang N. H. Tran: contribution: conducted laboratory experiments and involved in writing process; roles: conceptualisation, investigation, data curation, visualization and writing - original draft. Lee Graham: contribution: contributed to research design, critique and writing; roles: methodology, writing-review and editing. Emmanuel C. Adukwu: contribution: designed and supervised the research and involved in writing and evaluation of data; roles: conceptualization, supervision, visualization and writing - review and editing.

Data availability Not applicable.

\section{Compliance with ethical standards}

Conflict of interest The authors declare that they have no conflict of interest.

\section{Ethics approval and consent to participate Not applicable.}

\section{Consent for publication Not applicable.}

Open Access This article is licensed under a Creative Commons Attribution 4.0 International License, which permits use, sharing, adaptation, distribution and reproduction in any medium or format, as long as you give appropriate credit to the original author(s) and the source, provide a link to the Creative Commons licence, and indicate if changes were made. The images or other third party material in this article are included in the article's Creative Commons licence, unless indicated otherwise in a credit line to the material. If material is not included in the article's Creative Commons licence and your intended use is not permitted by statutory regulation or exceeds the permitted use, you will need to obtain permission directly from the copyright holder. To view a copy of this licence, visit http://creativecommons.org/licenses/by/4.0/.

\section{References}

Adukwu EC, Allen SC, Phillips CA (2012) The anti-biofilm activity of lemongrass (Cymbopogon flexuosus) and grapefruit (Citrus paradisi) essential oils against five strains of Staphylococcus aureus. J Appl Microbiol 113:1217-1227. https://doi.org/10.1111/j.13652672.2012.05418.x

Adukwu EC, Bowles M, Edwards-Jones V, Bone H (2016) Antimicrobial activity, cytotoxicity and chemical analysis of lemongrass essential oil (Cymbopogon flexuosus) and pure citral. Appl Microbiol Biotechnol 100:9619-9627. https://doi.org/10.1007/ s00253-016-7807-y

Almeida R, Navarro D, Barbosa-Filho J (2001) Plants with central analgesic activity. Phytomed 8:310-322. https://doi.org/10.1078/09447113-00050

Amorati R, Foti MC, Valgimigli L (2013) Antioxidant activity of essential oils. J Agric Food Chem 61:10835-10847. https://doi.org/10. 1021/jf403496k

Aneja KR, Joshi R, Sharma C (2009) Antimicrobial activity of Dalchini (Cinnamomum zeylanicum bark) extracts on some dental caries pathogens. J Pharm Res 2:1387-1390

Bajpai VK, Jung IY, Sun CK (2009) Antifungal potential of essential oil and various organic extracts of Nandina domestica Thunb. Against skin infectious fungal pathogens. Appl Microbiol Biotechnol 83: 1127-1133. https://doi.org/10.1007/s00253-009-2017-5
Ben-Ami R, Berman J, Novikov A, Bash E, Shachor-Meyouhas Y, Zakin S, Maor Y, Tarabia J, Schechner V, Adler A, Finn T (2017) Multidrug-resistant Candida haemulonii and C. auris, Tel Aviv, Israel. Emerg Infect Dis 23:195-203. https://doi.org/10.3201/ eid2302.161486

Boukhatem MN, Ferhat MA, Kameli A, Saidi F, Kebir HT (2014) Lemon grass (Cymbopogon citratus) essential oil as a potent antiinflammatory and antifungal drugs. Libyan J Med 9:25431. https:// doi.org/10.3402/ljm.v9.25431

Brnawi WI, Hettiarachchy NS, Horax R, Kumar-Phillips G, Seo HS, Marcy J (2018) Comparison of cinnamon essential oils from leaf and bark with respect to antimicrobial activity and sensory acceptability in strawberry shake. J Food Sci 83:475-480. https://doi.org/ 10.1111/1750-3841.14041

Brown GD, Netea MG (2007) Immunology of fungal infections. Springer, Dordrecht. https://doi.org/10.1007/1-4020-5492-0

Chen Y, Zeng H, Tian J, Ban X, Ma B, Wang Y (2013) Antifungal mechanism of essential oil from Anethum graveolens seeds against Candida albicans. J Med Microbiol 62:1175-1183. https://doi.org/ 10.1099/jmm.0.055467-0

Carvalho PCL, Sá NP, Lacerda ICA, Pataro C, Rosa LH, Alves RS, Lyon JP, Rosa CA, Johann S (2018) Anti-candida activity of cinnamon inhibition of virulence factors of clinical strains of Candida albicans by essential oil of Cinnamomum zeylanicum. PSM Microbiol 3:4 12

Chowdhary A, Voss A, Meis J (2016) Multidrug-resistant Candida auris: 'new kid on the block'in hospital-associated infections? J Hosp Infect 94:209-212. https://doi.org/10.1016/j.jhin.2016.08.004

Doyle AA, Stephens JC (2019) A review of cinnamaldehyde and its derivatives as antibacterial agents. Fitoterapia 11:104405. https:// doi.org/10.1016/j.fitote.2019.104405

Elcocks E, Spencer-Phillips P, Adukwu E (2020) Rapid bactericidal effect of cinnamon bark essential oil against Pseudomonas aeruginosa. J Appl Microbiol 128:1025-1037. https://doi.org/10. $1111 /$ jam. 14538

Espinel-Ingroff A, Chaturvedi V, Fothergill A, Rinaldi M (2002) Optimal testing conditions for determining MICs and minimum fungicidal concentrations of new and established antifungal agents for uncommon molds: NCCLS collaborative study. J Clin Microbiol 40:37763781. https://doi.org/10.1128/JCM.40.10.3776-3781.2002

Favero D, Furlaneto-Maia L, França EJ, Góes HP, Furlaneto MC (2014) Hemolytic factor production by clinical isolates of Candida species. Curr Microbiol 68:161-166. https://doi.org/10.1007/s00284-0130459-6

Gautam N, Mantha AK, Mittal S (2014) Essential oils and their constituents as anticancer agents: a mechanistic view. Biomed Res Int 2014. https://doi.org/10.1155/2014/154106

Gow NA, Brown AJ, Odds FC (2002) Fungal morphogenesis and host invasion. Curr Opin Microbiol 5:366-371. https://doi.org/10.1016/ S1369-5274(02)00338-7

Gruenwald J, Freder J, Armbruester N (2010) Cinnamon and health. Crit Rev Food Sci Nutr 50:822-834. https://doi.org/10.1080/ 10408390902773052

He M, Du M, Fan M, Bian Z (2007) In vitro activity of eugenol against Candida albicans biofilms. Mycopathologia 163:137-143. https:// doi.org/10.1007/s11046-007-0097-2

Khan MSA, Ahmad I (2011) Antifungal activity of essential oils and their synergy with fluconazole against drug-resistant strains of Aspergillus fumigatus and Trichophyton rubrum. Appl Microbiol Biotechnol 90:1083-1094. https://doi.org/10.1007/s00253-0113152-3

Khan MSA, Ahmad I (2013) In vitro inhibition of growth and virulence factors production in azole-resistant strains of non-albicans Candida by Cinnamomum verum, Cymbopogon citratus, Cymbopogon martini and Syzygium aromaticum essential oils. J Biol Act Prod Nat 3:139-153. https://doi.org/10.1080/22311866.2013.817729 
Khan MSA, Ahmad I, Cameotra SS (2013) Phenyl aldehyde and propanoids exert multiple sites of action towards cell membrane and cell wall targeting ergosterol in Candida albicans. AMB Express 3:54. https://doi.org/10.1186/2191-0855-3-54

Knobloch K, Pauli A, Iberl B, Weigand H, Weis N (1989) Antibacterial and antifungal properties of essential oil components. J Essent Oil Res 1:119-128. https://doi.org/10.1080/10412905.1989.9697767

Larkin E, Hager C, Chandra J, Mukherjee PK, Retuerto M, Salem I, Long L, Isham N, Kovanda L, Borroto-Esoda K, Wring S (2017) The emerging pathogen Candida auris: growth phenotype, virulence factors, activity of antifungals, and effect of SCY-078, a novel glucan synthesis inhibitor, on growth morphology and biofilm formation. Antimicrob Agents Chemother 6:e02396-e02416. https://doi. org/10.1128/AAC.02396-16

Leite MCA, Bezerra APDB, Sousa JPD, Guerra FQS, Lima EDO (2014) Evaluation of antifungal activity and mechanism of action of citral against Candida albicans. Evid-Based Complementary Altern Med 2014. https://doi.org/10.1155/2014/378280

Li WR, Shi QS, Liang Q, Huang XM, Chen YB (2014) Antifungal effect and mechanism of garlic oil on Penicillium funiculosum. Appl Microbiol Biotechnol 98:8337-8346. https://doi.org/10.1007/ s00253-014-5919-9

Lo HJ, Köhler JR, DiDomenico B, Loebenberg D, Cacciapuoti A, Fink GR (1997) Nonfilamentous C. albicans mutants are avirulent. Cell. 90:939-949. https://doi.org/10.1016/S0092-8674(00)80358-X

Lopes G, Pinto E, Andrade PB, Valentão P (2013) Antifungal activity of phlorotannins against dermatophytes and yeasts: approaches to the mechanism of action and influence on Candida albicans virulence factor. PLoS One 8:e72203. https://doi.org/10.1371/journal.pone. 0072203

Luo G, Samaranayake LP, Yau JY (2001) Candida species exhibit differential in vitro hemolytic activities. J Clin Microbiol 39:29712974. https://doi.org/10.1128/JCM.39.8.2971-2974.2001

Malcok HK, Aktas E, Ayyildiz A, Yigit N, Yazgi H (2009) Hemolytic activities of the Candida species in liquid medium. Eurasian J Med 41(2):95-98

Manns JM, Mosser DM, Buckley HR (1994) Production of a hemolytic factor by Candida albicans. Infect Immun 62:5154-5156

Mayaud L, Carricajo A, Zhiri A, Aubert G (2008) Comparison of bacteriostatic and bactericidal activity of 13 essential oils against strains with varying sensitivity to antibiotics. Lett Appl Microbiol 47:167173. https://doi.org/10.1111/j.1472-765X.2008.02406.x

Nayak AP, Green BJ, Beezhold DH (2013) Fungal hemolysins. Med Mycol 51:1-16. https://doi.org/10.3109/13693786.2012.698025

Prasad KN, Yang B, Dong X, Jiang G, Zhang H, Xie H, Jiang Y (2009) Flavonoid contents and antioxidant activities from Cinnamomum species. Innov Food Sci Emerg Technol 10:627-632. https://doi. org/10.1016/j.ifset.2009.05.009

Ranasinghe L, Jayawardena B, Abeywickrama K (2002) Fungicidal activity of essential oils of Cinnamomum zeylanicum (L.) and Syzygium aromaticum (L.) Merr et LM Perry against crown rot and anthracnose pathogens isolated from banana. Lett Appl Microbiol 35:208-211. https://doi.org/10.1046/j.1472-765X.2002. 01165.x

Raut JS, Karuppayil SM (2014) A status review on the medicinal properties of essential oils. Ind Crop Prod 62:250-264. https://doi.org/ 10.1016/j.indcrop.2014.05.055

Sanla-Ead N, Jangchud A, Chonhenchob V, Suppakul P (2012) Antimicrobial activity of cinnamaldehyde and eugenol and their activity after incorporation into cellulose-based packaging films. Packag Technol Sci 25:7-17. https://doi.org/10.1002/pts.952
Sardi JCO, Silva DR, Mendes-Giannini MJS, Rosalen PL (2018) Candida auris: epidemiology, risk factors, virulence, resistance, and therapeutic options. Microb Pathog 125:116-121. https://doi. org/10.1016/j.micpath.2018.09.014

Sardi JCO, Scorzoni L, Bernardi T, Fusco-Almeida A, Giannini MM (2013) Candida species: current epidemiology, pathogenicity, biofilm formation, natural antifungal products and new therapeutic options. J Med Microbiol 62:10-24. https://doi.org/10.1099/jmm.0. 045054-0

Sears D, Schwartz BS (2017) Candida auris: an emerging multidrugresistant pathogen. International J Infect Dis 63:95-98. https://doi. org/10.1016/j.ijid.2017.08.017

Shahina Z, El-Ganiny AM, Minion J, Whiteway M, Sultana T, Dahms TE (2018) Cinnamomum zeylanicum bark essential oil induces cell wall remodelling and spindle defects in Candida albicans. Fungal Biol Biotechnol 5:1-16. https://doi.org/10.1186/s40694-018-0046-5

Thompson DS, Carlisle PL, Kadosh D (2011) Coevolution of morphology and virulence in Candida species. Eukaryot Cell 10:1173-1182. https://doi.org/10.1128/EC.05085-11

Thosar N, Basak S, Bahadure RN, Rajurkar M (2013) Antimicrobial efficacy of five essential oils against oral pathogens: an in vitro study. Eur J Dent 7(Suppl 1):S71. https://doi.org/13057456.119078/1305-7456.119078

Topa SH, Subramoni S, Palombo EA, Kingshott P, Rice SA, Blackall LL (2018) Cinnamaldehyde disrupts biofilm formation and swarming motility of Pseudomonas aeruginosa. Microbiol. 164:1087-1097. https://doi.org/10.1099/mic.0.000692

Tworkoski T (2002) Herbicide effects of essential oils. Weed Sci 50:425431. https://doi.org/10.1614/0043-1745(2002)050[0425:HEOEO] 2.0.CO;2

Vaseeharan B, Thaya R (2014) Medicinal plant derivatives as immunostimulants: an alternative to chemotherapeutics and antibiotics in aquaculture. Aquac Int 22:1079-1091. https://doi.org/10. 1007/s10499-013-9729-3

Velluti A, Sanchis V, Ramos A, Egido J, Marın S (2003) Inhibitory effect of cinnamon, clove, lemongrass, oregano and palmarose essential oils on growth and fumonisin B1 production by Fusarium proliferatum in maize grain. Int J Food Microbiol 89:145-154. https://doi.org/10.1016/S0168-1605(03)00116-8

Velluti A, Sanchis V, Ramos A, Turon C, Marin S (2004) Impact of essential oils on growth rate, zearalenone and deoxynivalenol production by Fusarium graminearum under different temperature and water activity conditions in maize grain. J Appl Microbiol 96:716724. https://doi.org/10.1111/j.1365-2672.2004.02212.x

Wan L, Luo G, Lu H, Xuan D, Cao H, Zhang J (2015) Changes in the hemolytic activity of Candida species by common electrolytes. BMC Microbiol 15:171. https://doi.org/10.1186/s12866-015-05047

Yunes RA, Cechinel Filho V, Ferreira J, Calixto JB (2005) The use of natural products as sources of new analgesic drugs. Stud Nat Prod Chem 30:191-212. https://doi.org/10.1016/S1572-5995(05)80033$\mathrm{X}$

Zeng H, Chen X, Liang J (2015) In vitro antifungal activity and mechanism of essential oil from fennel (Foeniculum vulgare L.) on dermatophyte species. J Med Microbiol 64:93-103. https://doi.org/10. 1099/jmm.0.077768-0

Publisher's note Springer Nature remains neutral with regard to jurisdictional claims in published maps and institutional affiliations. 